\title{
Chapter 4 \\ Radioactive Cesium Contamination of Arthropods and Earthworms After the Fukushima Daiichi Nuclear Power Plant Accident
}

\author{
Sota Tanaka, Tarô Adati, Tomoyuki Takahashi, and Sentaro Takahashi
}

\begin{abstract}
To understand the behavior of radioactive cesium $\left({ }^{134} \mathrm{Cs}+{ }^{137} \mathrm{Cs}\right)$ in terrestrial invertebrates, chronological changes in the concentration of radioactive Cs in arthropods from different trophic levels were investigated after the Fukushima Daiichi Nuclear Power Plant accident. In addition, the level of radioactive Cs in earthworms, representing the detritivores, was also investigated. The median radioactive Cs concentration in the rice grasshopper (Oxya yezoensis) and the Emma field cricket (Teleogryllus emma) was 0.46 and $0.15 \mathrm{~Bq} / \mathrm{g}$ fresh weight (fw) in 2012, respectively, which dropped continuously to 0.05 and $0.01 \mathrm{~Bq} / \mathrm{g}$ fw in 2016 . In contrast, no significant reduction in radioactive Cs concentration was observed in the Jorô spider (Nephila clavata) in which the concentration was $0.31 \mathrm{~Bq} / \mathrm{g}$ fw in 2012 and remained at $0.14 \mathrm{~Bq} / \mathrm{g}$ fw in 2016. The comparison of radioactive Cs concentration at each trophic level showed that the amount in detritivorous earthworms was 85 times higher than in herbivorous grasshoppers. This suggests that detritus food web could be a primary pathway for migration of radioactive Cs through food webs.
\end{abstract}

\footnotetext{
S. Tanaka $(\bowtie)$

Kyoto University Graduate School of Agriculture, Kyoto, Japan

Research Group for Environmental Science, Nuclear Science and Engineering Center, Japan Atomic Energy Agency, Ibaraki, Japan

e-mail: tanaka.sota.57s@st.kyoto-u.ac.jp; tanaka.sota@jaea.go.jp

T. Adati

Department of International Agricultural Development, Faculty of International Agriculture and Food Studies, Tokyo University of Agriculture, Tokyo, Japan

T. Takahashi

Kyoto University Graduate School of Agriculture, Kyoto, Japan

Division of Radiation Control, Institute for Integrated Radiation and Nuclear Science, Kyoto University, Kumatori, Sennan, Osaka, Japan

S. Takahashi

Division of Radiation Control, Institute for Integrated Radiation and Nuclear Science, Kyoto University, Kumatori, Sennan, Osaka, Japan
} 
Keywords Grasshopper $\cdot$ Cricket $\cdot$ Spider $\cdot$ Earthworm $\cdot$ Radioactive cesium

\subsection{Introduction}

The accident at TEPCO's Fukushima Daiichi Nuclear Power Plant (FNPP) caused serious radioactive contamination across a wide area of eastern Japan. There is concern about the effect on the environment of cesium-134 $\left({ }^{134} \mathrm{Cs}\right)$ and $\mathrm{Cs}-137\left({ }^{137} \mathrm{Cs}\right)$, with the relatively long half-life $\left({ }^{134} \mathrm{Cs}, 2.06\right.$ years; ${ }^{137} \mathrm{Cs}, 30.17$ years $)$. In Fukushima Prefecture, approximately $71 \%$ of the total land area is covered with forests [1]. Therefore, a large proportion of the radioactive $\mathrm{Cs}\left({ }^{134} \mathrm{Cs}+{ }^{137} \mathrm{Cs}\right)$ released into the atmosphere was deposited onto the forested areas. Over time, the radioactive Cs accumulates in the soil surface layer and is maintained long-term in the soil organic layer. Thus, the organic layer of soil represents a major pool of radioactive Cs in forest ecosystems [2]. Radioactive Cs can then circulate throughout the forest ecosystem by biological processes [3] as is in the same elemental family as potassium, an essential element for all organisms.

Arthropods have a large biomass and are important food sources for other organisms such as birds, amphibians, reptiles and mammals. Terrestrial arthropods are also important seasonal diets for freshwater fishes such as trout $[4,5]$ and act as a trophic linkage across the forest-stream ecosystem [6]. This supports the hypothesis that terrestrial arthropods could be a carrier of radioactive Cs throughout the food web and a route of transfer or radioactive Cs between the forest and aquatic ecosystems.

Earthworms function as ecosystem engineers [7] to produce a homogenized organic soil layer. This bioturbation activity is an important factor in the long-term behavior of radioactive $\mathrm{Cs}$ in the soil [8]. Earthworms are also important food resources for various organisms. Therefore, determining radioactive Cs concentration in arthropods and earthworms is important for understanding the long-term behavior of radioactive $\mathrm{Cs}$ in the ecosystem and for radiation risk assessment for non-human species. However, the number of reports on radioactive contamination in arthropods and earthworms after the FNPP accident is limited (Table 4.1) [9-19].

We reported the chronological changes in radioactive Cs levels in common terrestrial arthropod species from different trophic levels after the FNPP accident. The report showed a continuous annual reduction of radioactive $\mathrm{Cs}$ in herbivorous grasshoppers and omnivorous crickets, in contrast to carnivorous spiders in which no significant reduction in radioactive Cs was observed from 2012 to 2014 . These differences in radioactive $C s$ at each trophic level over time suggest that the level of contamination of the varied food resource pathways is different [15].

The present study shows the latest data on the chronological changes of radioactive Cs concentration in the arthropods over the 5-year period from 2012 to 2016. Furthermore, in order to investigate the detritus food web which has been suggested to act a major transfer pathway of radioactive Cs in the food web [10, 16], detritivorous earthworms were investigated in 2014, and radioactive Cs concentration among species with different feeding habits was compared. 
Table 4.1 Reports on radionuclide contamination in arthropods and earthworms after the FNPP accident

\begin{tabular}{l|l|l|l}
\hline Target & Radionuclide & $\begin{array}{l}\text { Collection } \\
\text { year }\end{array}$ & References \\
\hline Spider & ${ }^{134} \mathrm{Cs},{ }^{137} \mathrm{Cs}$ & 2012 & Ayabe et al. [9] \\
\hline $\begin{array}{l}\text { Various organisms including } \\
\text { arthropods }\end{array}$ & ${ }^{137} \mathrm{Cs}$ & 2012 & Murakami et al. [10] \\
\hline Aquatic insects in a stream & ${ }^{134} \mathrm{Cs},{ }^{137} \mathrm{Cs}$ & $2012-2013$ & $\begin{array}{l}\text { Yoshimura and Akama } \\
\text { [11] }\end{array}$ \\
\hline $\begin{array}{l}\text { Various organisms including } \\
\text { spider }\end{array}$ & $\begin{array}{l}{ }^{134} \mathrm{Cs},{ }^{137} \mathrm{Cs}, \\
\text { Spider }\end{array}$ & $2011-2014$ & Nakanishi et al. [12] \\
\hline $\begin{array}{l}{ }^{110 \mathrm{~m}} \mathrm{Ag} \\
\text { arthropods }\end{array}$ & ${ }^{134} \mathrm{Cs},{ }^{137} \mathrm{Cs}$ & $2012-2013$ & Ayabe et al. [13] \\
\hline Spider, cricket, grasshopper & ${ }^{137} \mathrm{Cs}$ & $2012-2013$ & Sakai et al. [14] \\
\hline Forest insects & ${ }^{134} \mathrm{Cs},{ }^{137} \mathrm{Cs}$ & $2012-2014$ & Tanaka et al. [15] \\
\hline Earthworm & ${ }^{137} \mathrm{Cs}$ & $2012-2013$ & Ishii et al. [16] \\
\hline Earthworm & ${ }^{134} \mathrm{Cs},{ }^{137} \mathrm{Cs}$ & 2011 & Hasegawa et al. [17] \\
\hline Earthworm & ${ }^{134} \mathrm{Cs},{ }^{137} \mathrm{Cs}$ & $2011-2013$ & Hasegawa et al. [18] \\
\hline
\end{tabular}

\subsection{Materials and Methods}

\subsubsection{Sampling Site and Measurement of Ambient Dose Equivalent Rate}

The sampling site is located $40.1 \mathrm{~km}$ northwest of FNPP (latitude, $37^{\circ} 41^{\prime} 35^{\prime \prime} \mathrm{N}$; longitude, $140^{\circ} 44^{\prime} 08^{\prime \prime} \mathrm{E}$; Fig. 4.1). This area is composed of a hilly and mountainous landscape with agricultural fields and residential areas surrounded by mountainous forests. Residents were still not permitted to live in this area during the study period from 2012 to 2016.

Ambient dose equivalent rate was measured at multiple points on the sampling site using a NaI scintillation survey meter (TCS171, Hitachi, Ltd., Japan) placed $1 \mathrm{~m}$ above the ground, and the distance of each measurement point was at least $20 \mathrm{~m}$.

\subsubsection{Sampling of Arthropods and Earthworms}

Three arthropod species, the rice grasshopper (Oxya yezoensis), the Emma field cricket (Teleogryllus emma) and the Joro spider (Nephila clavata) were collected by sweep-net sampling and hand collection from September to October of each year between 2012 and 2016. For each arthropod species, we collected 20-200 individuals each year. Epigeic earthworms were collected by hand collection in October 
Fig. 4.1 Location of the sampling site and FNPP

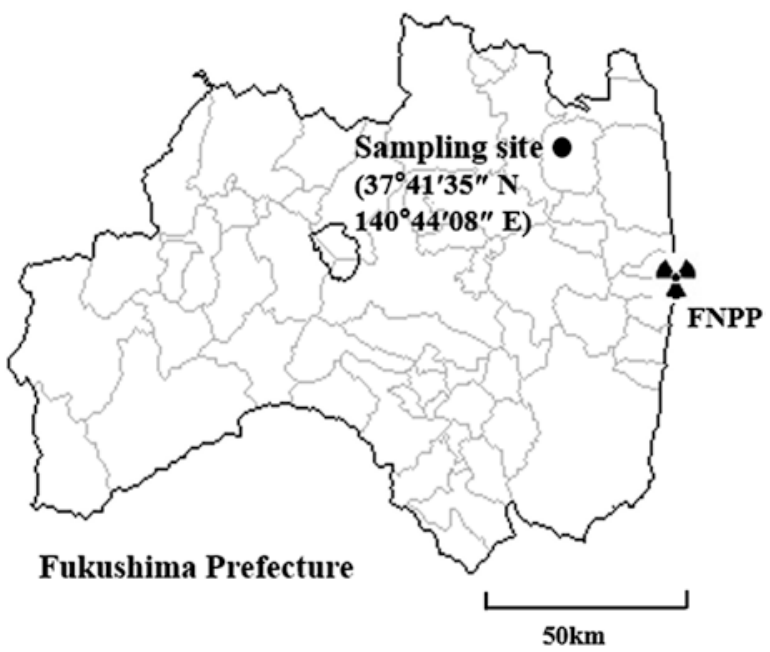

2014. All of the sampled arthropods and earthworms experience a generational turnover once a year.

\subsubsection{Measurement of Radioactive Cs Levels in Samples}

Gamma-ray spectrometry was conducted using a high-purity germanium detector (GC-2020, Canberra Industries, and GEM30-70, ORTEC, USA) with a multichannel analyzer (MCA, DAS1000, Canberra Industries, and Easy-MCA-8k, ORTEC, USA). The counting efficiency of the detector was determined by measuring a certified mixed radioactive standard gamma volume source (MX033SPLU8, Japan Radioisotope Association, and 24FY039, Japan Chemical Analysis Center). All samples were placed into $100 \mathrm{ml}$ plastic containers (U-8), and the radioactivity of the samples was obtained as $\mathrm{Bq} / \mathrm{g}$ fresh weight $(\mathrm{Bq} / \mathrm{g}$ fw).

\subsubsection{Statistical Analyses}

For changes in ambient dose equivalent rate and radioactive Cs concentration in arthropods and earthworms, the lower $\left(Q_{1}\right)$ and upper $\left(Q_{3}\right)$ quartiles and the interquartile range $\left(\mathrm{IQR}=Q_{3_{-}} Q_{1}\right)$ were calculated. Differences in the values among years were analyzed with a Kruskal-Wallis test using R version 2.15.3 [20]. 


\subsection{Results}

\subsubsection{Ambient Dose Equivalent Rates at the Sampling Site}

Ambient dose equivalent rate at the sampling site is shown in Fig. 4.2. The median ambient dose equivalent rate showed significant reductions from 3.74 to $1.29 \mu \mathrm{Sv} / \mathrm{h}$ between 2012 and 2016 (Kruskal-Wallis test, $P<0.05$ ). The decrease during the initial phase of the survey period from 2012 to 2013 was $29 \%$, and the later phase from 2015 to 2016 was only $4 \%$. The total reduction in the median ambient dose equivalent rate during the survey period from 2012 to 2016 was calculated to be $65 \%$.

\subsubsection{Chronological Changes in Radioactive Cs Levels in Arthropods}

The change in radioactive Cs concentration in three arthropod species over the 5 -year investigation is shown in Fig. 4.3. The median concentration of radioactive Cs in grasshoppers significantly decreased from 0.46 to $0.05 \mathrm{~Bq} / \mathrm{g}$ fw between 2012 and 2016 (Kruskal-Wallis test, $P<0.05$; Fig. 4.3A). Field crickets also showed a significant decrease in radioactive Cs concentration from 0.15 to $0.01 \mathrm{~Bq} / \mathrm{g}$ fw $(P<0.05 ;$ Fig. 4.3B). In contrast, the median concentration of radioactive Cs in Jorô spiders was not significantly different during the survey period ( $P=0.14$; Fig. $4.3 \mathrm{C}$ ); the median of radioactive Cs concentration from 2012 to 2016 were $0.31,0.33$, $0.20,0.23$, and $0.14 \mathrm{~Bq} / \mathrm{g} \mathrm{fw}$, respectively. The decrease in median radioactive Cs

Fig. 4.2 The ambient dose equivalent rate $(\mu \mathrm{Sv} / \mathrm{h}$ at $1 \mathrm{~m}$ above ground) significantly differed over time after the FNPP accident (Kruskal-Wallis test, $P<0.001)$. Minimum and maximum values of dose rate are depicted by whiskers plots. The box signifies the upper and lower quartiles, and the median is represented by a horizontal line within the box for each year

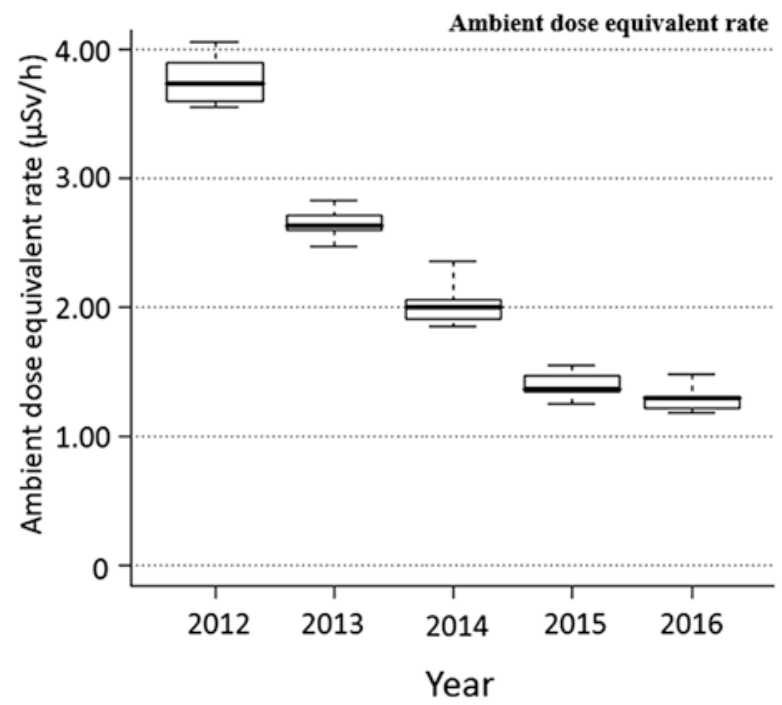



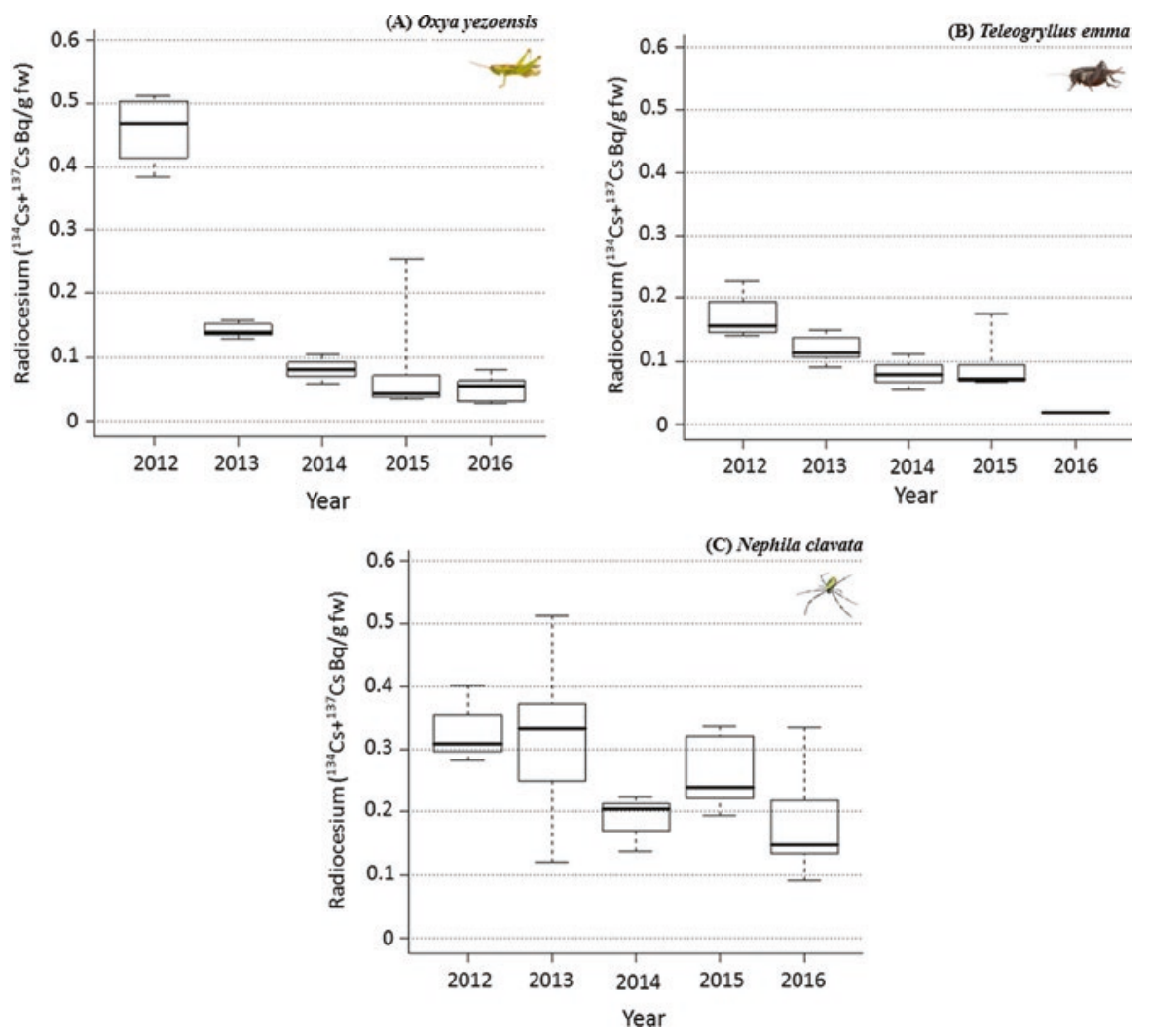

Fig. 4.3 Radioactive Cs concentration (Bq/g fw) in the rice grasshopper (Oxya yezoensis) $(\mathbf{A})$, and the Emma field cricket (Teleogryllus emma) (B), significantly changed over time after the FNPP accident (Kruskal-Wallis test, (A) $P=0.002$; (B) $P=0.003$ ). However, no significant changes were observed in the Joro spider (Nephila clavata) $(\mathbf{C}: P=0.149)$. Minimum and maximum concentrations are depicted by whisker plots. The box signifies the upper and lower quartiles, and the median is represented by a horizontal line within the box for each year

concentration from 2012 to 2016 was calculated to be $88 \%, 87 \%$, and $52 \%$ for grasshoppers, field crickets, and Jorô spiders, respectively.

\subsubsection{Comparison Between Different Feeding Habits and ${ }^{137} \mathrm{Cs}$ Concentration}

Radioactive Cs concentration in grasshoppers, field crickets, Jorô spiders and earthworms was compared in 2014. The median of ${ }^{137} \mathrm{Cs}$ concentration in earthworms was $4.87 \mathrm{~Bq} / \mathrm{g}$ fw, which was about 85 times higher than that of grasshoppers, and over 30 times higher than that of Jorô spiders, which showed the highest level of radioactive Cs among the three arthropod species examined (Fig. 4.4). 
Fig. 4.4 Comparison of radioactive $\mathrm{Cs}$ concentration between different feeding habits in 2014

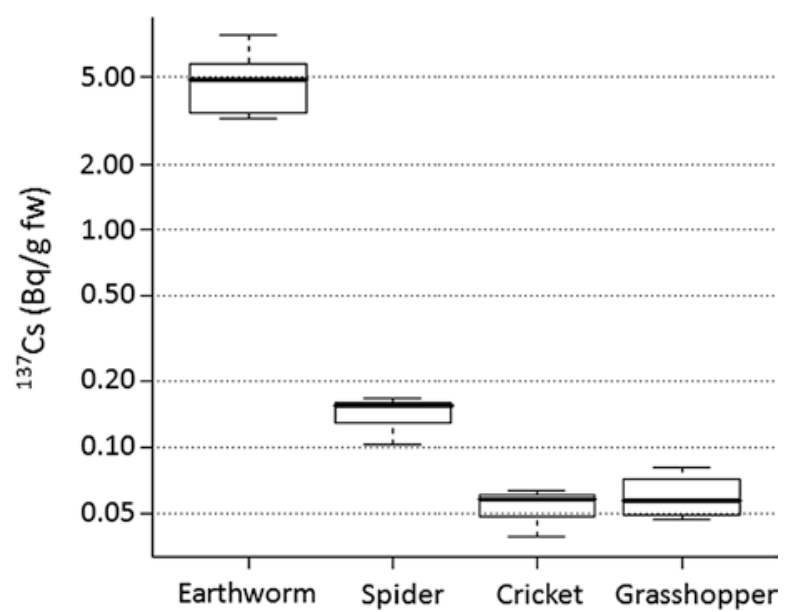

\subsection{Discussion}

The ambient dose equivalent rate at the sampling site significantly decreased from 2012 to 2016. The $\gamma$-ray contribution of ${ }^{134} \mathrm{Cs}$ to ambient dose equivalent rate is higher than ${ }^{137} \mathrm{Cs}$ [21], and the physical half-life of ${ }^{134} \mathrm{Cs}$ is shorter than that of ${ }^{137} \mathrm{Cs}$. Therefore, the reduction in the ambient equivalent dose rate during the initial phase after the accident determined in the present study is mainly attributed to the physical half-life of ${ }^{134} \mathrm{Cs}$, although the weathering effect may also contribute to the decrease. From 2015 to 2016, the decrease in ambient equivalent dose rate at the sampling site was only $4 \%$, which was lower than the $29 \%$ decrease during the initial phase from 2012 to 2013. This suggests that the yearly rate of decrease in the ambient dose equivalent rate at the time of this study will remain for a long time even at the low levels.

The median radioactive $\mathrm{Cs}$ concentration in the grasshoppers and field cricket significantly decreased from 2012 to 2016. In contrast, the concentration in Jorô spiders did not differ significantly during the survey period. These trends are consistent with our previous report from 2012 to 2014 [15]. The radioactive Cs concentration in Jorô spiders showed relatively wide variation during the 5-year sampling period, and the median radioactive Cs concentration in Jorô spiders remained at 52\% between 2012 and 2016. Different food resource pathways, such as grazing and detrital food web, likely caused this trend [22]. As herbivorous, grasshoppers rely on the grazing food web, and their radioactive Cs concentration showed a rapid decrease. These indicate that radioactive Cs transfer from the grazing food web is not a dominant long-term contributor in grasshoppers. In contrast, carnivorous web spiders rely on both the grazing and detritus food webs due to the variety of prey items captured by their orb web. The variation in radioactive Cs in Jorô spiders during the 5-year survey period indicated that they use both the grazing and detritus food webs. The relationship between feeding habits and radioactive Cs levels 
showed that earthworms, representing the detritivores, had radioactive Cs levels about 85 times higher than grasshoppers which rely on the grazing food web. We reported that the ${ }^{137} \mathrm{Cs}$ concentration in the earthworms remained stable from 2014 to 2016 [19]. These findings clearly indicate that the detritus food web is more highly contaminated than the grazing food web. High levels of ${ }^{137} \mathrm{Cs}$ accumulation flow up to higher trophic levels through the detritus food web [10]. Therefore, the high levels of radioactive Cs concentration maintained in Jorô spiders during this study period could be explained by their food resources coming from the contaminated detritus food web. In forests, the biomass of aerial insects from the detrital food web increases in spring and autumn, and web spider depends on these aerial insects [23]. In the present study, Jorô spiders were collected in autumn between September and October; thus the food resources of Joro spiders were relatively dependent on the detritus food web during the collection period. This study thus demonstrates that the detritus food web is the primary pathway for long-term movement of radioactive $\mathrm{Cs}$ through the food web. Moreover, the detritus food web makes a large contribution to the transfer and circulation of radioactive Cs within the ecosystem. From a long-term perspective, the behavior of radioactive Cs through the food web, including these invertebrate species, is important for understanding the environmental behavior of radioactive $\mathrm{Cs}$ and accurate radiation risk assessment for non-human species.

\subsection{Conclusions}

A 5-year study in arthropods showed variations in the chronological change of radioactive Cs concentration levels among arthropods of different trophic levels. The radioactive Cs concentration in both herbivorous grasshoppers and omnivorous field crickets significantly reduced from 2012 to 2016. In contrast, the level in carnivorous Jorô spiders did not change significantly during the survey period. This variance is likely caused by the difference in food resource pathways between the grazing food web and the detritus food web (Fig. 4.5). Detritivorous earthworms showed the highest radioactive Cs concentration, and the comparison between trophic levels and radioactive Cs concentration clearly showed high contamination in the detritus food web. This study demonstrates that the detritus food web is the primary pathway for long-term radioactive Cs movement through the food web. Long-term monitoring of terrestrial invertebrates is thus necessary to understand the behavior of radioactive $\mathrm{Cs}$ in the ecosystem and to contribute to risk assessment for non-human species. 


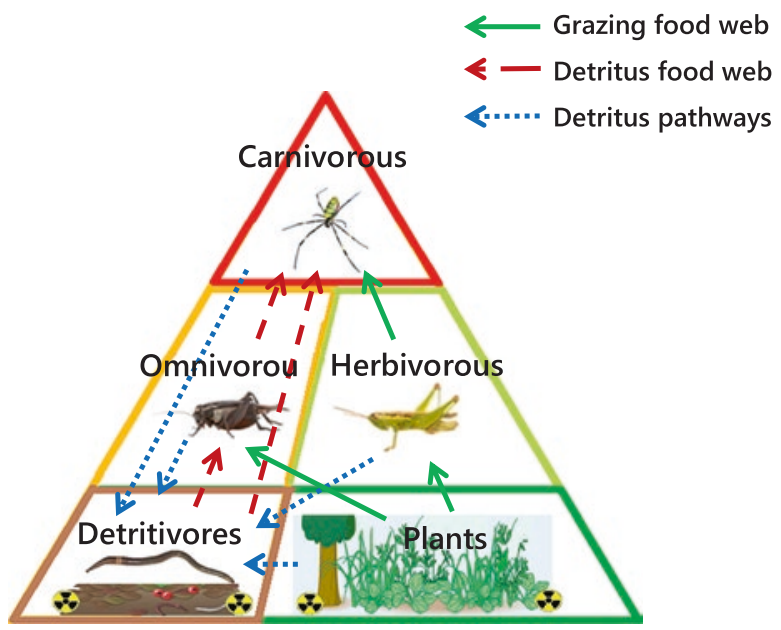

Fig. 4.5 Transfer pathways of radioactive Cs in terrestrial invertebrates. Each species represents feeding habits of terrestrial invertebrates; thus each species does not always prey on each other directly. For example, web spider cannot prey earthworm, but they can prey detritivores such as flies (Diptera) which emerge from the same habitat of earthworm. Therefore, earthworm represents radioactive Cs contamination in detritivores, and the other three species also represent the contamination of each feeding habit

\section{References}

1. Fukushima Prefectural Government (2015) Forest and Forestry Statistics. http://www.pref. fukushima.lg.jp/sec/36055a/toukeisyo.html. Accessed 1 Mar 2018

2. Steiner M, Linkov I, Yoshida S (2002) The role of fungi in the transfer and cycling of radionuclides in forest ecosystems. J Environ Radioact 58:217-241

3. Myttenaere C, Schell WR, Thiry Y, Sombre L, Ronneau C, van der Stegen de Schrieck J (1993) Modelling of Cs-137 cycling in forests: recent developments and research needed. Sci Total Environ 136:77-91

4. Wipfli MS (1997) Terrestrial invertebrates as salmonid prey and nitrogen sources in streams: contrasting old-growth and young-growth riparian forests in southeastern Alaska, U.S.A. Can J Fish Aquat Sci 54:1259-1269

5. Sato T, Watanabe K, Kanaiwa M, Niizuma Y, Harada Y, Lafferty KD (2011) Nematomorph parasites drive energy flow through a riparian ecosystem. Ecology 92:201-207

6. Nakano S, Miyasaka H, Kuhara N (1999) Terrestrial-aquatic linkages: riparian arthropod inputs alter trophic cascades in a stream food web. Ecology 80(7):2435-2441

7. Lavelle P, Bignell D, Lepage M, Wolters W, Roger P, Ineson P, Heal OW, Dhillion S (1997) Soil function in a changing world: the role of invertebrate ecosystem engineers. Eur J Soil Biol 33:159-193

8. Tyler AN, Carter S, Davidson DA, Long DJ, Tipping R (2001) The extent and significance of bioturbation on137Cs distributions in upland soils. Catena 43:81-99. 5

9. Ayabe Y, Kanasashi T, Hijii N, Takenaka C (2014) Radiocesium contamination of the web spider Nephila clavata (Nephilidae: Arachnida) 1.5 years after the Fukushima Dai-ichi Nuclear Power Plant accident. J Environ Radioact 127:105-110

10. Murakami M, Ohte N, Suzuki T, Ishii N, Igarashi Y, Tanoi K (2014) Biological proliferation of cesium-137 through the detrital food chain in a forest ecosystem in Japan. Sci Rep 4:1-5 
11. Yoshimura M, Akama A (2013) Radioactive contamination of aquatic insects in a stream impacted by the Fukushima nuclear power plant accident. Hydrobiologia 722:19-30

12. Nakanishi H, Mori A, Takeda K, Tanaka H, Kobayashi N, Tanoi K, Yamakawa T, Mori S (2015) Discovery of radioactive silver $(110 \mathrm{mAg})$ in spiders and other fauna in the terrestrial environment after the meltdown of Fukushima Dai-ichi nuclear power plant. Proc Jpn Acad Ser B Phys Biol Sci 91:160-174

13. Ayabe Y, Kanasashi T, Hijii N, Takenaka C (2015) Relationship between radiocesium contamination and the contents of various elements in the web spider Nephila clavata (Nephilidae: Arachnida). J Environ Radioact 150:228-235

14. Sakai M, Gomi T, Negishi JN, Iwamoto A, Okada K (2016) Different cesium-137 transfers to forest and stream ecosystems. Environ Pollut 209:46-52

15. Tanaka S, Hatakeyama K, Takahashi S, Adati T (2016) Radioactive contamination of arthropods from different trophic levels in hilly and mountainous areas after the Fukushima Daiichi nuclear power plant accident. J Environ Radioact 164:104-112

16. Ishii Y, Hayashi S, Takamura N (2017) Radiocesium transfer in forest insect communities after the Fukushima Dai-ichi nuclear power plant accident. PLoS One 12:1-14

17. Hasegawa M, Ito MT, Kaneko S, Kiyono Y, Ikeda S, Makino S (2013) Radiocesium concentrations in epigeic earthworms at various distances from the Fukushima Nuclear Power Plant 6 months after the 2011 accident. J Environ Radioact 126:8-13

18. Hasegawa M, Kaneko S, Ikeda S, Akama A, Komatsu M, Ito MT (2015) Changes in radiocesium concentrations in epigeic earthworms inrelation to the organic layer 2.5 years after the 2011 Fukushima Dai-ichi nuclear power plant accident. J Environ Radioact 145:95-101

19. Tanaka S, Adati T, Takahashi T, Fujiwara K, Takahashi S (2018) Concentrations and biological half-life of radioactive cesium in epigeic earthworms after the Fukushima Dai-ichi Nuclear Power Plant accident. J Environ Radioact 192:227-232

20. R Core Team (2013) R: a language and environment for statistical computing. R Foundation for Statistical Computing, Vienna Austria ISBN 3-900051-07-0. http://www.R-project.org

21. IAEA (International Atomic Energy Agency) (2000) Generic procedures for assessment and response during a radiological emergency. Iaea-Tecdoc- 1162 .

22. Polis GA, Strong DR (1996) Food web complexity and community dynamics. Am Nat 147(5):813-846

23. Shimazaki A, Miyashita T (2005) Variable dependence on detrital and grazing food webs by generalist predators: aerial insects and web spiders. Ecography (Cop) 28:485-494

Open Access This chapter is licensed under the terms of the Creative Commons Attribution 4.0 International License (http://creativecommons.org/licenses/by/4.0/), which permits use, sharing, adaptation, distribution and reproduction in any medium or format, as long as you give appropriate credit to the original author(s) and the source, provide a link to the Creative Commons license and indicate if changes were made.

The images or other third party material in this chapter are included in the chapter's Creative Commons license, unless indicated otherwise in a credit line to the material. If material is not included in the chapter's Creative Commons license and your intended use is not permitted by statutory regulation or exceeds the permitted use, you will need to obtain permission directly from the copyright holder.

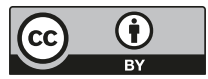

